\begin{tabular}{|c|}
\hline 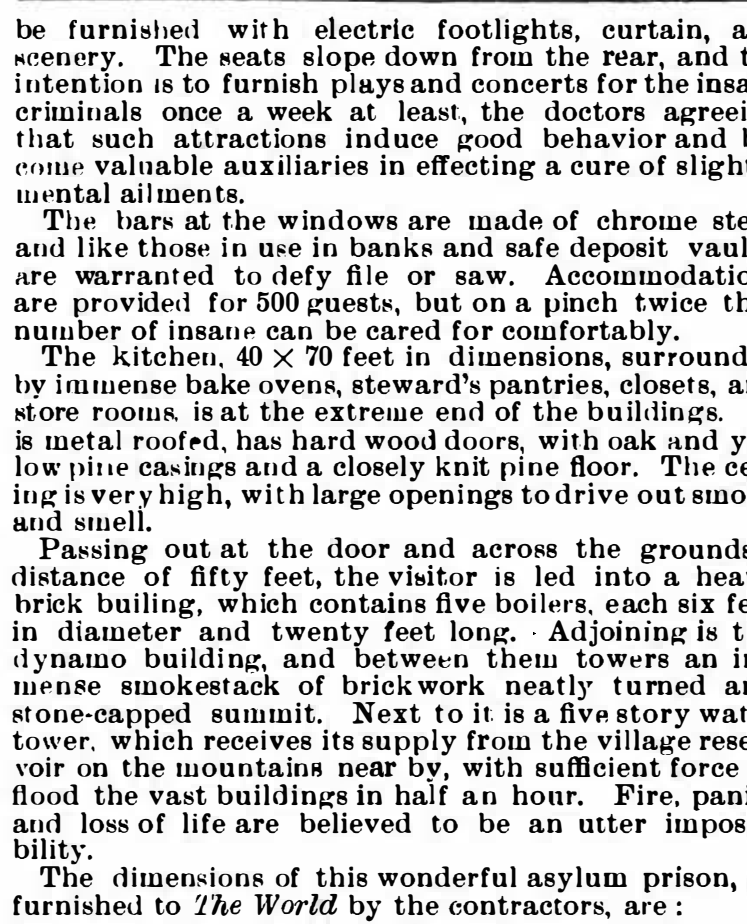 \\
\hline
\end{tabular}

The work of contractors Sullivan \& Clarke cost $\$ 810,000$, exclusive of grading, lighting, heating, and plumbing. The electric light plant, with wiring and
lamps, cost $\$ 50,000$, and the reniainder of the $\$ 1,000,000$ expended by the State was devoted to the purchase of land, preparing it with drainage and plumbing, heat trees will be planted on the grounds, and in a few years
it will be one of the garden spots on the Hudson it will be one of the
River.-N. Y. World

\section{BARUSCOPIC THERMOMETER.}

UP to the present, all thermometers, other than mercurial and alcoholic ones, have zenerally been by expansion. The instrunent that may be regarded
as the type of this kind is Breguet's imetallic theras the type of this kind is Breguet's metallic ther molneter.
These apparatus all offer the same inconvenience; after operating a certain length of time, the dilatable successive twistings, certain wolecular modifleations that change the structure of it, so that the same variation of cemperature no longer affects it in the same way
that it did at the time that the apparatus was graduated. The readings are therefore no longer accurate. and the effects becouning marked in the long run, the instrument is put out of service.
The object of thermometers of

kind is to obtain capable of being easily seen at a distance, or to estab lish contacts with determined points. Now, in order that the movable object may be capable of being dis-
placed, it is necessary that it shall be submitted to the perature, and such force has generally

The baroscopic thermometer is desigued to overcome such irregularities of operation, through the use of a motive force which, really invariable, always produces the same effects for the same causes.

This force is gravity. In this apparatus there is utilized the weight of the volume to which the body expands; in other words, instead of employing, as an
initial force, the breaking of the geometrical equilib-
rium of a body, we utilize the breaking of its static equilibrium in assimilating the expansible body to a balance, that is to say, to a lever of the first kind, one of the arms of which is formed of the expansible mamaterial. It is evident that, with the elevation of the temperature, the second lever arm will increase in descend, and we shall here have a utilizable force. If care be taken to select for an expansible body a material not subject to molecular variations of structure,
it is clear that to a same elevation of temperature there will always correspond a like expansion and therefore a same motive fore

a same motive force. perfectly adapts it to the construction of the apparatus, and the uniformity of expansion of which secures a perfectly regular operation. Moreover, the great
density of this metal gives a great increase of force for a slight increase of temperature. In principle, the baroscopic thermometer devised by held in equilibrium by means of a horizontal axis pass-
ing through it 8 center of gravity. If the temperature rises, the mercury will expand in the thermometric
tube, which will become more weighty and will incline. tube, which will become more weighty and will incline. In case the temperature falls, a contrary effect will fol-
low, and the tube will rise, thus producing an alternatlow, and the tube will rise, thus producil
ing inotion capable of being utilized.

The principle upon which the baroscopic thermo-

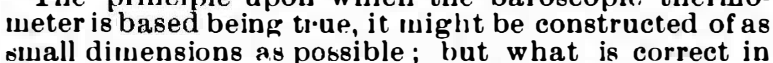
theory ceases to be so in practice when it is necessary to dispose of an appreciable force in order to render for the work absorbed by the movement of the part.s.

The inventor was therefore led to give the mercurial reservoir quite large dimensions, in order that the $\alpha$ being the

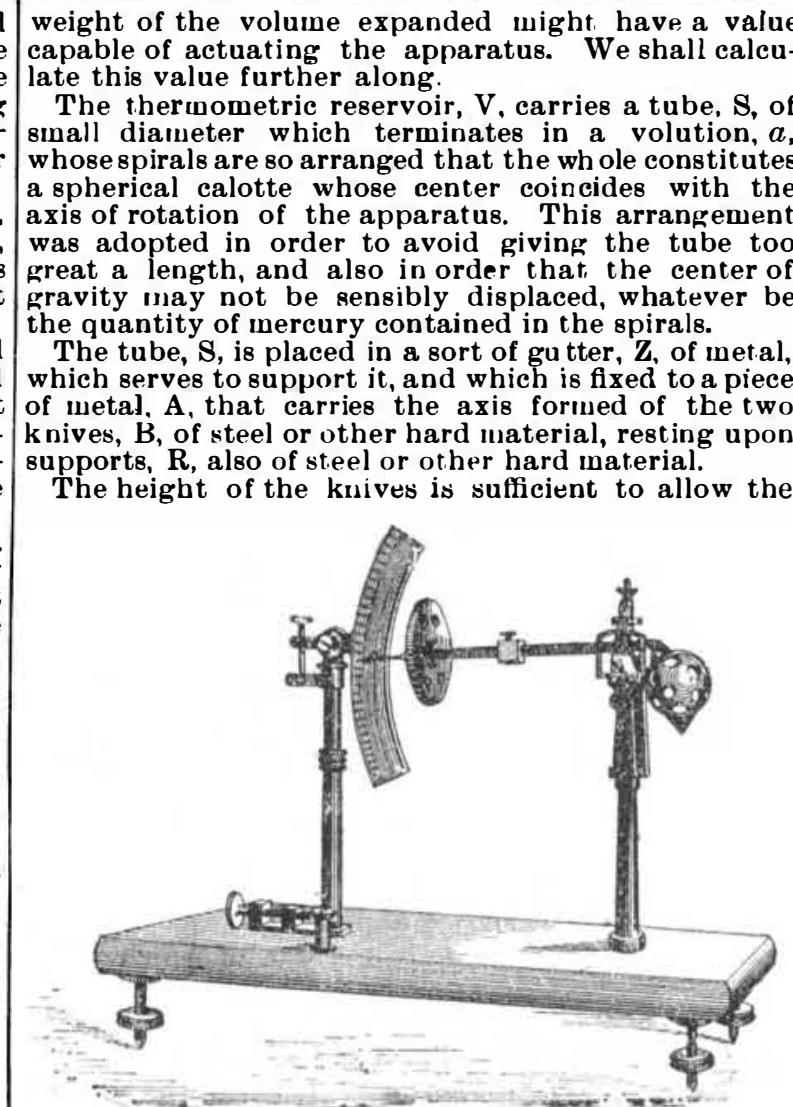

FIG. 1.-DEBAEGKER'S BAROSCOPIC THERMOMETER.

horizontal axis of rotation, constituted by the conjunction of the knives and supports, to be situated a
little above the center of gravity of the apparatus. A regulating screw, M, placed at the upper part of the
piece, A, permits of varying the sensitiveness. In the piece, A, permits of varying the sensitiveness. In the
center of the spherical calotte formed by the spirals there may be fixed either an indicating needle, $E$, or any movable device capable of producing contacts, if
it be desires to use the thermometer for indicating the variations of temperature at a distance. However,
the inventor is now putting the last touches on a very complete registering apparatus designed to be Cuated by the thermoneter.

Calculation of the Thermometric Reservoir, V.-In
order to simplify this calculation, we shall take cunt only of the expansion of the mercury contained in the reservoir, without occupying ourselves with that
which is in the small tube, and the expansion of which Let $f$ be the motive force that it is desired to ob-
ingen tain for a variation of $1^{\circ}$ of temperature, and let $\frac{1}{m}$ be the ratio existing between the distances that separate, rom the center of gravity of the reservoir and from the
rom center of gravity of the small tube and its spherical If we deduct from the reservoir a weight, $p$, the ef
ct. produced is the same as if there had been added to the long arm a weight $\frac{p}{m}$. On another hand, if we

We dedace from this :

$$
\begin{gathered}
\mathrm{V}=\frac{v}{\alpha} \\
\mathrm{V}=\frac{m \cdot f}{\alpha \cdot 2(m+1)}
\end{gathered}
$$

It will be seen from formula (1) that the difference o weight of the quantity of mercury displaced act so much the less force in proportion as the ratio is greater; but this arrangement has been employed in order to render the apparatus lighter, a nd therefore
more sensitive. The maximum effect will be obtained more sensitive. The maximum effect will be obtained with arms of equal length, for
act with a force equal to $2 p$.

In order to establish the graduations, the formula of
act with a force the sensitiveness of the balance is taken as a basis - a

by the beam for a given load. the mass of which requires a certain tine to take the emperature, it would be possible to adopt a spiral re-

Finally, in order to render the apparatus lighter,
mercury uight be left only in the long arm, and the pansible. But this arrangement would diminish the precision of the instrument. Moreover, it has bnen
tried already without much success. - Le Genie Civil.

THE PRACTICAL APPLICATION OF MAGNESIA CEMENT.*

By Carl OtTo Weber, Ph.D.

THE name of cement is applied to a certain class of chowler coupounds which, when in the form of a fin solid homogeneous muss of stone-like appearance and great hardness. One class of these cements, which we way roughly term alumina-lime silicates, hasdeveloped nto an industry of the highest importance, producin millions of tons every year, although it is hardly 70 products on a large scale. The literature, scientific nd technical, of this branch of chenical manufacturot very astonishing if we convider. on the one hand the commercial importance of the article, on the other hand the very great complexity of this watter from a

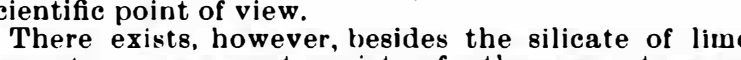
cements, a very great variety of other cements, some ng, neither commercially nor scientifically, nterest us. As competitors with the alumina lime silicates they are altogether out of the question. But there is a class of cements, the magnesia cements,
which certainly are deserving of more attention than has been paid to them up to now, although I do not mean to say that they will ever rival ordinary cemen
in any considerable degree. But on the other hand here can be no doubt that these cements might easily find a considerable sale, so soon as the means are found o overcome certain unwelcome properties of them, which are the main impediment to their use. The hydraulic properties of magnesium oxide have been discovered by Vical, the same man who may be ndustry. Vical observed that freshly calcined inag. nesia hardens in contact with water, au observation which was confirmed by Macleod, but neither of the two seems to have followed up this experiment any when Deville discovered that magnesia, obtained from lime formed a cement which under water sets to a mas now add to this arm thissame weight, $p$, it will act with $\begin{aligned} & \text { in its outer appearance ver.y much like marble, but } \\ & \text { considerably surpassing this material in hardness. }\end{aligned}$

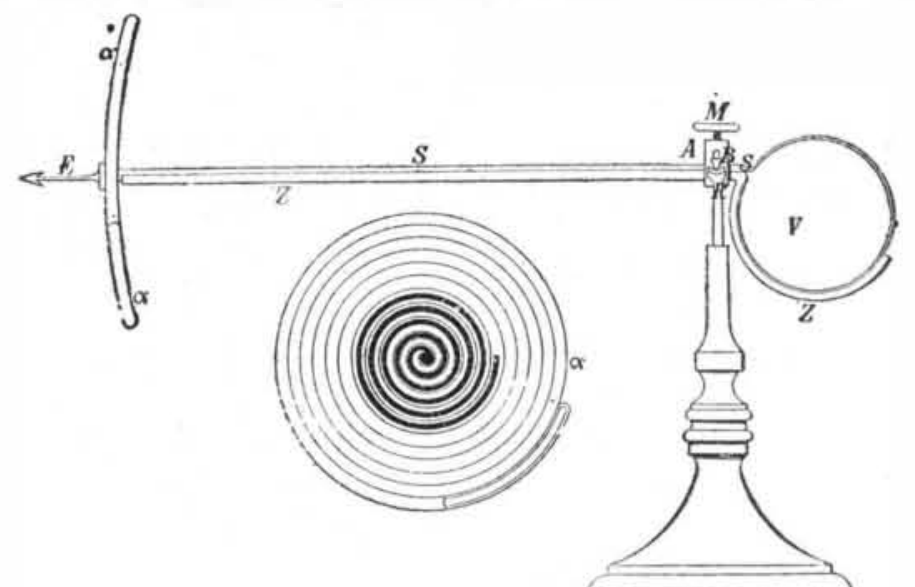

Fig. 2.--Diagram OF BAROSCOPIC THERMOMETER.

force equal to its own value, and the total effect pro- Deville found that the hardness these cements attain duced to influence the tube will be equal to $p+\frac{p}{m}$

(1)

We shall therefore have Magnesia salts precipitated with alkalies yield a mag-
nesia of great hardness, forming cements of a very poor of magnesiun by the uagnesia obtained density. To use Deville's method for the production of this ceiment on a comm ercial scale is out of the question for economical reasons. But considering the composition of Deville's cement, magnesia and carbonate of lime, it is not surprising that experinents have been made with bonate, for the manufacture of the product in quesIf dolomite is heated to a temperature below red heat, the carbonic acid of the magnesia carbonate, but not of the lime carbonate, is $g$ iven off and the resultir.g product is Deville's cement. On further investizahydraulic properties of this cement increase with the *Lately read before the Manchester Section, Society os Chetaical
Induatry. 
proportion of magnesiat which it contains, and that in strength and durability it is equal to a good average
Portland cement. This standard, however, was subse quently contradicted by Erdmenger, who found these
dolomite cements very much inferior to the average Portland cements.
The interest which this class of magnesia cement at one time attracted by and by subsided, and to-day the question of dolomite cements has sunk nearly into ob-
livion. If we take into consideration that dolomite cements could be profitably produced at about two
thirds of the price of Portland cements, it is obvious that their qualities must be of such an unsatisfactory
kind as to render them unfit for successful competition with the silicate of lime cements. with the silicate of lime cements. on the magnesia lime carbonate cements, Sorel disas magnesium oxy-chloride. He produced it by
forming a paste from a finely ground magnesium oxide and a solu tion of magnesium chloride from 30 to
70 per cent. strong. This cement, which sets tolerably 70 per cent. strong. This cement, which sets tolerably
quickly, forming a very hard mass, considerably harder crushing test, and possesses a tensile strength equal to crushing test, and possesses a tensile strength equal to
four time ton per square inch, which is about three or
four the tensile strength of a good Portland cement. producing splendid concretes with as unch as ten times beautiful white color, so that it appears scarecly doubt. ful that if magnesia is going to win a place among
the important cements, it will be in the form of Sorel s cement or some improvement thereon.

Une of the most important items to be observed with magnesia cement is to use a magnesia of great
density and as free as possible from carbonic acid. A
few per cent. of carbonic acid absorbed by the biurnt and powdered magnesia are sufficient to so consider. useless. The reason of this is, not that the magnesium carbonate formed, by its chemical properties, prevents the formation of a cement from the unchanged magnesia
on the interaction of the solution of chloride of magon the interaction of the solution of chloride of mag-
nesium, but that the magnesium carbonate envelops nesium chloride, and although in the center of each film of carbonate prevents the action from particle to particle, $i$. e., the agglomeration of the whole mass. A
few days' exposure of the magnesia to the atmosphere few days' exposure of the magnesia to the atmosphere
is quite sufficient to make this substance unfit for use. The magnesium chloride used for Sorel's cement is
the ordinary product as it is used largely in textile inthe ordinary product as it is used largely in textile inblock of white color and crystalline texture,containing
about 48 per cent. of pure $\mathrm{MgCl}_{2}$. Of this salt Sore recommends the use of a solution from 30 to 70 per
cent. strong, but I found the results obtained are the cent. strong, but I found the results obtained are the
more satisfactory the stronger the solutions used, and

strong.
If from magnesia and such an 80 per cent. solution of magnesinm chloride a paste is formed, it sets within still increases for some days. The time of setting to a
great extent depends upon the temperature and the great extent depends upon the temperature and the
moisture of the air at the time the experiment is made, high temperature and little moisture considerably accelerating the setting, whereas low temperature
and moist atmosphere show a decidedly restraining influence.
The proportions of magnesia and magnesium chloride are of the greatest influence upon the qualities of the was the harder the stronger the solution of inagnesium chloride used, and this fact was already pointed out by Sores himeelf. This might seem to imply that the ing the proportion of magnesium chloride which enters
in the composition. But this is not so. The fact is in the composition. But this is not so. The fact is
that in working the cement with an 80 per cent. soluthat in working the cement with an 80 per cent. solu-
tion of magnesium chloride, the strength of the cement The following series of experiments show this very clearly :

\begin{tabular}{|c|c|c|c|}
\hline No. & MgO & $\begin{array}{l}\mathrm{MgCl}_{2} 6 \text { aq. } \\
30 \text { Per cent. Sol. }\end{array}$ & $\begin{array}{l}\text { Tensile Strength } \\
\text { Inch } \text { Per } \\
\text { Square. }\end{array}$ \\
\hline $\begin{array}{l}1^{*} \\
3 \\
4 \\
5 \\
5\end{array}$ & $\begin{array}{l}10 \\
10 \\
10 \\
10 \\
10\end{array}$ & $\begin{array}{r}6 \\
8 \\
10 \\
12 \\
14\end{array}$ & $\begin{array}{l}1,748 \\
1,300 \\
1,150 \\
1,028 \\
860\end{array}$ \\
\hline
\end{tabular}

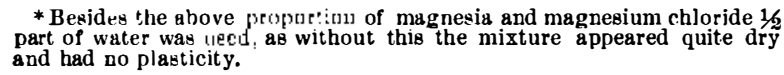

This shows distinctly enough that a mere increase
in the proportion of the magnesium chloride is detrimental to the cement, a fact which becomes still more prominent some time after the experiment, when first !
hair cracks appear on No. 5 sample, which in due time develop into gaping fissures, owing to a swelling of the
cement after setting. Samples 3 and 4 show the same phenomenon, only in a somewhat smaller degree, the
amount of swelling being distinctly in proportion to the amount of magnesium chloride the samples con-
tain. Samples 1 and 2 remain perfect for any length tain. Samples 1 and
Considering these facts, we must come to the conConsidering these facts, we must come to the con-
clusion that if the stronger chloride solution produces stronger cements than a weaker chloride solution, this is not due to the relative increase in magivesium chloride,
hut to the decrease of the water of the solution. The
correctness of this conclusion is borne out by another correctness of this conclusion is borne out by another
series of experiments. Sample No. 1 of the previous series of experiments. Sample No. 1 of the previous
series showed the highest tensile strength and stability, and to find out the influence of water, or what comes
to the same, of solutions of magnesium chloride less than 80 per cent. strong. I added to the various cement
mixtures varying quantities of water:

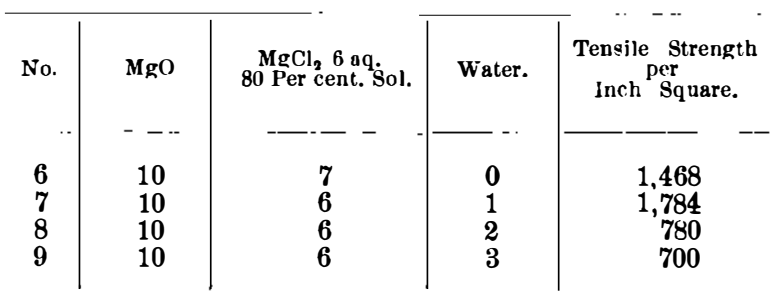

Nos. 6 and 7 test were only made to check the corcordance with them. Test No. 8 contains the same proportions of maguesia and magnesium chloride as
test No. 7 , but double the quantity of water, and the result is a cement not half as strong as the latter : and
still worse is No. 9 with 3 parts of water, notwithstand still worse is No. 9 with 3 parts of water, notwithstand
ing the fact that the quantity of magnesium chloride
is the same in each of the three samples. Sample No. 7 never shows any swelling or hair cracks, but the san-
ples No. 8 and No. 9 are in this respect as bad if not whe Nom samples No. 4 and No. 5 .
worse than bad if not
These results show that the water of the solution of These results show that the water of the solution of magnesium chloride plays a very important part in
these cements, and acts not simply as a solvent. This is further shown by the fact that a solution of mag
nesium chloride in absolute alcohol does not form any cement with magnesia, no matter how long it is in conSorel considered his cement simply as an oxychloride
cluded. Sorel considered his cement simply as an oxychloride
of magnesium, but this compound, very probably, does
not exist at all. All the samples I described contain a not exist at all. All the samples 1 described contain a
very considerable quantity of water, of which only a
very swall part is given off at $100^{\circ} \mathrm{C}$. and even at $200^{\circ}$ C. not more than 70 per cent. of the total water the
cement contains is expelled. From this we have to conclude that the setting of Sorel's magnesia cement is
one and the same process as the setting of the Portland one and the same process as the setting of the Portland cements, $i$. e.. assimilationty being
similation evidently bing chloride.

According to this, we shall have to describe this toment as hydroxychloride of magnesium. Bender,
my knowledge, was the first to point this out. Bender evidently used a magnesium chloride solution
containing about 50 per cent. $\mathrm{MgCl}_{2} 6$ aq., as the com-
position answered the formula $\mathrm{MgCl}_{2}+5 \mathrm{MgO}+17$

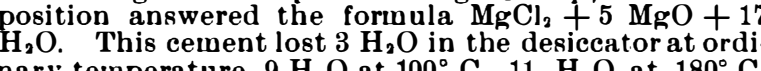
nary temperature, $9 \mathrm{H}_{2} \mathrm{O}$ at $100^{\circ} \mathrm{C}$., $11 \mathrm{H}_{2} \mathrm{O}$ at $180^{\circ} \mathrm{C}$.
On treating the cement with cold water, it lost $\mathrm{MgCl}_{2}$, On treating the cement with cold water, it lost $\mathrm{MgCl}_{2}$,
and the composition of the remainder answered the
formula $\mathrm{M}_{2} \mathrm{Cl}_{2}+9 \mathrm{MgO}+24 \mathrm{H}_{2} \mathrm{O}$. Boiling water re-

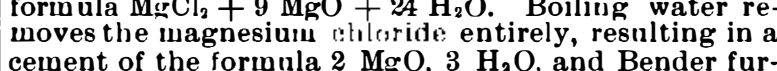
cement of the formula $2 \mathrm{MgO}, 3 \mathrm{H}_{2} \mathrm{O}$, and Bender fur
ther adds that neither the treatment with cold nor
with hot water has lomerated cement.

glomerated cement.
My experiments do not corroborate this statement, nor is it in accordance with the results of the experi-
ments made on a large scale with Sorel's cement It perfectly correct that water extracts $\mathrm{MgCl}_{2}$ from the
cement, which assimilates a proportionate amount of water, but this reaction invariably destroys the ag water be used. This effect, produced by the action of water, makes Sorel's cement utterly useless for outdoor purposes, where it would be exposed to the influence experiments on a large scale. The Union Stone Com-
pany in Boston. U. S A, used Sorel's cement for the wanufacture of artificial stones and emery wheels, and How the emery wheels turned out is not stated, but awn afraid the results were not very gratifying, as my Sorel's cement are rather dangerous in use. They may
or some time run right enongh, and work extremely ell, but they suddenly burst without any ap-
parent cause. These very serious drawbacks are suffiient explanation that Sorel's cement, in spite of it
heap price and other advantages, is very little used. cheap price and other advantages, is very little used.
If instead of the magnesium chloride, a substance
could be found which would form an insolnble comcould be found which would form an insolible com-
pound with magnesia and at the same time have the same active properties with regard to the hydration of forthwith take its place as a cement of the first order
admirably adapted for the wanufacture of artificial
stones for building, ornamental, and a number of other purposes. Already Sorel hinted that magnesium
chloride might bedispensed with and other compounds chloride inight bedispensed with and other compounds
used instead, but at the same time he did not mention any compound better suited to the purpose than mag. nesium chloride. I experimented with chloride of
potassium and chloride of sodium, both of which act potassium ar way as the chloride of magnesium, but
certainly with no better results. The chlorides of the alkaline earths do not answer at all, nor do any of the is a decided action by silicic acid, or such of the
silicates which, being treated with hydrochloric acid. produce gelatinous silicic acid. I experimented with and anhydrous silicic acid, the last two named pro-
duced from a solution of silicate of soda by addition oced from a solution of silicate of soda by addition
of hydrochloric acid. The silicates I used were silicate
of soda, silicate of magnesia, and silicate of lime. of soda. silicate of magnesia, and silicate of lime.
Powdered flint, as will be expected, showed extremely little, if any, action, although it had been most carefully incorporated to the magnesia, the cement it pro-
duced took considerable time in setting, and was only moderately strong. Infusorial earth gave considerably better results, the cement setting very quickly and show-
ing considerable hardness and strength. Hydrosilicic acid acted so suddenly that it was past the inaximum of sia. Precipitated anhy properly wixed witl the magneof the series, producing after ten hours' setting a very
hard and in every respect very strong cerneut of perfect. ly white color. Silicate of soda forms with magnesia a paste which very soon hardens, without, however, prosilicates of magnesia and lime behave very much like
the soda silicate, but take a longer time to set than the latter. Of the whole series, the precipitated anhy-
hydrous silicic acid showed to best effect, and was further proceeded with. A series of experiments was
wade to ascertain the best proportion of wagnesia and silicic acid :

\begin{tabular}{|c|c|c|c|c|}
\hline No. & $\mathrm{MgO}$. & $\mathrm{SiO}_{2}$ & $\begin{array}{c}\text { Time for setting. } \\
\text { in } \\
\text { Hotrs. }\end{array}$ & $\begin{array}{l}\text { T'ensile Streng,h } \\
\text { Inch Square. }\end{array}$ \\
\hline $\begin{array}{l}10 \\
11 \\
12 \\
13 \\
14 \\
15\end{array}$ & $\begin{array}{l}100 \\
100 \\
100 \\
100 \\
100 \\
100\end{array}$ & $\begin{array}{c}5 \\
7 \\
10 \\
15 \\
: 20 \\
30\end{array}$ & $\begin{array}{l}32 \\
24 \\
15 \\
14 \\
13 \\
19\end{array}$ & 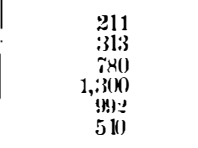 \\
\hline
\end{tabular}

To get reliable results it is necessary to incorporate the silicic acid with the magnesia as carefully as possi-
ble, otherwise the repetitions of one and the same test may nearly as widely differ in the figure representing the tensile strength as any two of the above test This shows that about 15 per cent. of silicic acid are
Pow required to give the best result as regards the strength
of the cement. Test No. 14 was quicker in setting. but of the cement. Test No. 14 was quicker in setting, but
considerably weaker. But even No. 15, the strongest we found for the magnesium chloride cements : but on the other hand. these cements made with silicic acid are perfectly indifferent against water. cold or hot, and difficulty in the practical use of these cements would boon after exposure to the atmosphere. Two or three soon after exposure to the atmosphere. Two or three
hours' exposure I found quite sufficient to nearly anniThis is certainly a very serious drawback, as in practica use it would mean a great deal of waste $;$ but it can be with a solution of magnesium chloride instead of water he cement thus formed sets in about ten hours, and forms an extremely hard wass: which in strength even
surpasses Sorel's cement. without sharing the unwel. ome properties of the latter. Water takes up unagneexpansion is noticeable. 'Treatment with cold water is quite sufficient to extract all the magnesium chlo-
ride, the place of which in the cement is taken by water hydrating the magnesia.
The admixture of silicic acid with Sorel's magnesia cement makes the latter closely related to the hydrau. ic mortars as well as the Portland and Roman cement, as the formation of a hydraulic magnesium silicate in that mixture is beyond doubt. On treatwent of this
new cement, after setting, with hydrochloric acid, it slowly decomposes. The whole of the magnesia and uch a cement are in solution, the rest of the silici portions for the preparation of this new cement und to be :

100 magnesia.

90 magnesi uu chloride solution, 80 per cent.

This cement is of a tensile strength equal to $1,78 \mathrm{llb}$. per inch square, the most important part being the done as carefully as possible. Absorption of carbonic acid previous to use to the extent of about two per cent. has scarcely any effect upon it; a larger propor-
tion acts in precisely the same manner as in the other

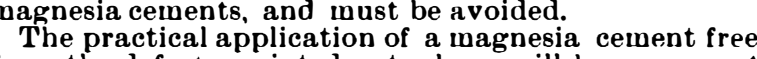
rom the defects pointed out above will be very great
ndeed, owing to its cheapness, remarkably fine color and great agglomerating capacity, many times surpassexperience goes, magnesia cement is a material of the
first order for the manufacture of artificial stones for ordinary building and ornamental purposes, for the manufacture of emery wheels, and for the production
of artificial lithographic stones. Only in the first of
these applications named can it be said to enter into competition with Portland cement, the other applications being altogether beyond the scope of the latter.
Whether magnesia cement will ever be capable of collpeting with Portland cement in general concreting to give an opinion yet, but it may interest you to hea gine beds, the results also from an economical poin

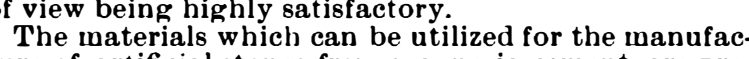
Tre of artificial stones from unannesia ce thent are pre-
terably such containing silica or silicates. Sand, crushed granite, porphyry, glass, Yorkshire and Cheshire sandstones. and the like answering very well. The quantity of cement to be used depends very little on
the chemical nature of the filling-up material, but is very considerably influenced by the coarser or finer wixtures attain is, however, quite independent of the
degree of granulation, as under all circumstances we are able to produce from any of the above filling-up
materials with magnesia cement a composition very
much stronger than the cement itself. This seems a very remarkable fact, and a few examples may serve
to illustrate it. I used in the following series of experiments emery. simply because this material is readily grains varying in size from $1 / 4$ of $u n$ inch (emery No. 6) to $\frac{1}{60}$ of an inch (emery No. 200 or emery floury. The
samples were al ways tested one week after thes had been made, as it was found that after this tine they
gain in four toonths about tive per cent. only in trength.

'I'his series clearly shows the remarkable fact above
eferred to, $i$. e. that wixtures of wagnesia cemunt and referred to, i. e., that mixtures of wagnesia cempnt aud
ndifferent wineral materials produce compositious at
last as strong as the cement itself, and eventually twiee
as strong. But this result is subject to certain condiions, the most important of which is that the cement nixture used must be such as to allow each particle of it, after which the mixture wust remain of a rather
moist, not dry and sticky, appearance. There are, of course, two ways of arriving at this end, the one he
ing to use a rather thin flowing cement mixture to start 
with, or to use a larger quantity of a drier cement commercial importance, as up to now the trade in
mixture. Of these two ways, I found the first to lithographic stones is imonopolized by the Bavarian give the better result. The strongest cement inixture
I produced is No. 1, viz., 10 parts of magnesia and 6 of

magnesium chloride solution; these proportions produce a very dry mixture, and you will see that in com-
bination with emery it yields a composition very much inferior in tensile strength to a similar combination made with No. 3 cement, although the latter in its pure state is very wuch weaker than No. 1 . Experiments but you see how the strength is increased simply by
using larger proportions of it, that is making the combing larger proportions of it, that is making the combortance of this point is still better illustrated by using
the finer emery, 24 or 36 . You wil! notice that the 20 per cent. compositions, Nos. 16. 20, and 23 , show a great par cent. compositions, Nos. 16, 20, and 23, show a great
lation of the ementh borresponding to the finer granucent. compositions, No8. 18, 22, and 25, show the salle strength. By using more than 40 per cent. of the cement mixture no further increase in strength is ob-
tained: on the contrary it begins to decrease, and at about 80 per cent. the combined mixtures show the same strength as the corresponding pure cement.
Emery flour, however, forms the exception of the rule as it reaches its maximum strength with 60 per cent.
cement. It never attains the strength we could obtain cement. It never attains the strength we could obtain
with eoarser material, but on the other hand we reach with eoarser material, but on the other hand we reach
the mimimum strength, that is the strength of the emery flour. Cement No. 1 forming an exceedingly stiff paste, it is quite clear that, although it is about the strongest give satisfactory results in combination with indifferent materials. Of course it might appear that its ex duced as to give it the required fluidity, but if you look at experiment No. 28. which represents the strong-; you will see, although it is mich stronger than the cor-
responding experiment No. 19, still it remains consilererably behind the strength of the pure cement. Thi might still be accounted for by deficient fluidity, and ment No. 29, you see that the result shows the contrary of an improvement. This is evidently due to the periments 8 and 9 , and also by N.o. 30, which otherwise corresponds to No. 18 .

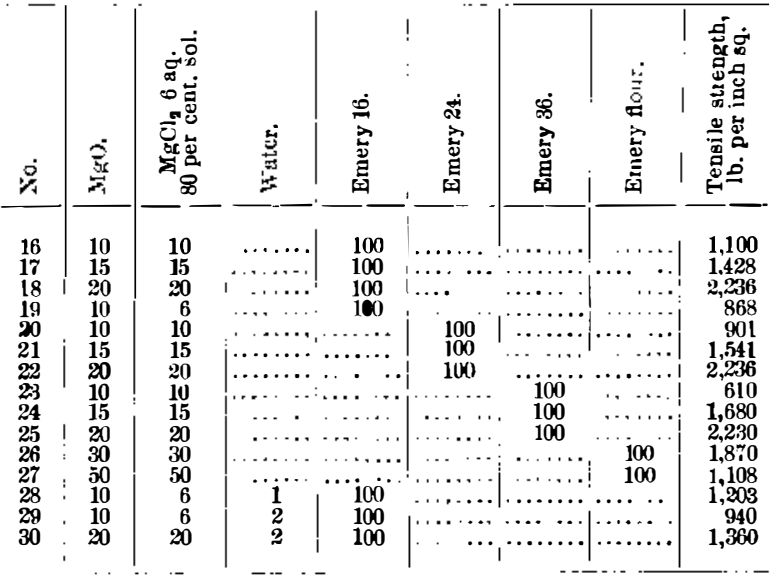

Considering the great strength of compounds of mag-

nesia cement, it will appear that it is very well adaptit has been used for this purpose for some time; but such an emery wheel is scarcely safe enough in use, for
reasons I pointed out before. If, however. to Sorel's magnesia cement the silica magnesia cement be subness, and perhaps as safe as the emery wheels consider
ed the safest of all, namely, those made with India rubber as cohesive matter. The proportion of cement in the magnesia emery whe els ought not to be less tha 20 per cent. of the emery; it never exceeds 50 per cent. for the manufacture of millstones. The face of these rushed flint. Such millstones are in hardness, lastin quality, and general efficiency very much superior to natural stones, especially for the grinding of very hard material. For corn grinding they are not so well
adapted, though they are used very extensively for the The future of the magnesia cement seems, however to lie in its application for the manufacture of artificial building stones, as very small percentages of the ceneart are required to form remarkably strong stones. pose, and especially good results can be obtained with mixtures of sand and not too coarse pebble or
gravel. The stones may be colored, or given an ornamental face backed by ordinary material; in this way stones are obtained which at very moderate cost reunost important question with regard to these stones is
of course whether they will resist the influence of the atmosphere as well as a good natural building stone. A ar as artificial stones from Sorel cement are concerned stones made from the silica of magnesia cement withstood the influence of the atmosph ere forover 12 months without showing the slightest sign of deterioration will find some which have been exposed for a con
siderable period without in any way looking the worse for it.
$A$ few experiments which $I$ made with a view to produce artificial lithographic stones proved very success-
ful, in so far as the stone I obtained behaved in practical use in every respect like the natural lithographic
stones from the Bavarian quarries, but did not yield the same number of impressions as the latter. This
difficulty, however, I consider not very difficult to overcome, as it merely seems to be a question of the
absorbing qualities of the stone. The artificial pro-
duction of these stones would be a matter of no surall
[NATURE.]

PHOTOGR.APHIC PERSPECTIVE AND THE USE OF ENLARGEMENT.

IT is not uneommon to hear it remarked that photographs make hills look low, or that they make things
ook " such a long way off ;" and that they do so in a In explanation of the apparent lowness of phot
In graphed mountains, I have heard it suggested that the erent standards, and this, too, is probably the case but since there is a horizontal and a. vertical in a pic-
ture as well as in nature, the eye ought to form similar .

The true meaning of the appearances alluded to
though they admit of a most simple explanation, is not The fact is that they depend be expected.

The fact is that they depend merely on perspective In elementary books on arawing there often appears
a diagram in which imaginary threads are supposed point behind it. The trace of these threads on the the perspective, when viewed from the intersection of the threads; and if the proper amount of light, shade,
and color be supposed to be added, this picture, to the and color be supposed to be added, this picture, to the Bishable from the object itself.

Bnt now suppose the eye is not at the place of inter-
ection of the threads, but a certain distance farthe section of the threads, but a certain distance farther
rent or nearer to the glass. It is evident that the appa-
rent angular magnitude of every object in the picture 8 altered in the ratio of the distance of the intersection of the threads to the distance of the eye from the glass.
But this is exactly what would be the case if, keeping the eve at the intersection of the threads, a new

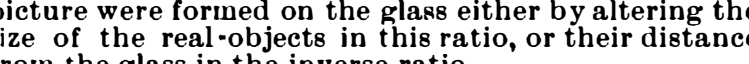

For instance, let the objects forming the picture be two towers, one say half a mile off and the other a
mile, and suppose that the intersection of the threads same angle as they do in reality; but if the eye be
moved a foot further from the glass, these angles will be halved, and the same picture will then fall on the retina as would be formed there were the eye one foot
from the glass and the towers only half their actual
size, or if they were removed to the distances of one uile and two miles respectively.

Thus by viewing the picture from the wrong distance
either the apparent size of the objects represented by it is multiplied by ratio $\frac{\text { true distance }}{\text { wrong }}$ distance , or their apparent distances by wrong distance

Putting this in symbols, for the sake of simplicity and brevity, we have, if $\mathrm{D}=$ true distance of an
object from the point of view, $\mathrm{A}=$ its real linear magnitude, $F=$ distance at which the picture must be
viewed in order to convey a correct impression of $D$ and $A$. Then if $d$ and $a$ are the values corresponding
to $D$ and $A$ when the pinture is seen from the distance $f$, we have $d=\frac{f}{\mathrm{~F}} \mathrm{D}$ when $\mathrm{A}$ is judged correctly $=\frac{F}{f} A$ when $D$ is judged correctly. Of course both A and $D$ muy be misjudged, but apparent and tr
distances in sizes are still connected by the relation $a d=\mathrm{AD}$.

In a photograph, $\mathbf{F}$ is the focal length of the len
with which it was taken, and $f$ the distance at whic it is looked at. Thus, if, as is generally the case with is less than the distance one would naturally hold the
picture at for convenient view, the inevitable result i gither that the apparent distances of the picture
greater than the real ones in the proportion of $\frac{f}{F}$, that the apparent sizes of the things represented in are reduced in the proportion $\frac{F}{f}$, or a combination of Which theseng impressions is produced.

is suggested depends wuch on the nature of the picIn interiors taken with a wide-angle, short-focused
int lens, distances are enormously exaggerated, while in As a rule, it way be said that objects which do not themselves suggest any scale will be made to look
mall, while those which do, such as men, houses, etc. will appear distant.

When $\frac{\mathrm{F}}{f}$ is greater than unity, $i . e$. , when the picThe magnif ying power of a telescope is the focal
length of the object-glass divided by the focal length length of the object-glass divided by the focal length of the eye-piece, or, in other words, the distance from
the lens at which the image is formed divided by, the
distance from which it is viewed. distance from which it is viewed.
If the focal length of the eye-piece is the same a in the field of the telescope will be seen an exact When, however, by shortening the focal length of
Whation of of all the distances in the ratio $\frac{\mathbf{F}}{f}$ naturally takes place. This may bo practically illustrated in rathox a atrik an upright sheet of glass, and to intersect in some is one foot behind the gluss; to the eye placed at that
distance the towers in the picture will subtend the cure is viewed too near, the reverse of the above effect
is seen ; and as far as the perspective is concerned, the straight piece of line at an approaching train.
along a Supposing the train to be traveling at forty miles
per hour, if the telescopic power be forty, the a pparent per hour, if the telescopic power be forty, the apparent
rate of approanh will be only one mile per hour. From what has been said, it will be clear that just
the same laws apply to photographic pictures (or any pictures in true perspective) as to telescopic images, convey a correct impression to the eye.
This being so, it is evident that any photograph taken with a lens of less than about a foot focal length
must exaggerate all the distances, or make objects in the picture look smaller than they should, and the right distance to view it from becomes also the convenient distance.
Even if this be done, however, there is still a tendency to view the picture too far off ; for few lenses, except those for portraits, embrace an angle so small
as to be taken in at a single glance, and people are naturally inclined to stand far enough from a picture to see the whole of it at once. best ineans of making a photograph give a true idea of
and the scene which it represents; and this is especially
true of the small pictures taken by so-called "detective" cameras, having lenses varying from four to six inches in focal length ; and it is for this end, and not,
in general, to enable more detail to be seen, that the nlarging process is most useful.

Of course, negatives for enlargement must be well enough defined to bear being examined from the focal
distance of the lens which took them, or less than this distance of the lens which took them, or less than this
(since detail is lost in the enlarging process), and many (8ince detail is lost in the enlarging process), and many or more off will be found imperfect when looked at In a subsequent article I will, if the editor permits, enter more fully on the subject of photographic definition and its limits, both as they depend on the nature
of the various sensitive films and on the lenses by

AN INCANDESCENT LAMP FACTORY IN THE NORTHWEST.

By W. Forman Coluins

AMONG the new and important industries of the North west, a section of the country that has had an
unprecedented and remarkably rapid growth during unprecedented and remarkably rapid growth during Appleton, Wisconsin. The new company is strongly
backed financially and the field for its operation i backed financially and the field for its operation is very extensive, as evinced by the large volume of busi-
ness already being done by the new concern, although The writer having been cordially invited to inspect
Then the new lamp industry has embodied his observations it is hoped, will prove of interest and possibly instruc-
tive to those not versed in the process of incandescent lamp manufacture.
The factory of the company is located on the Fox River, on the lower dam, and comprises three buildinge, the largest of which is $150 \times 80$ and three stories high, the others being somewhat sumaller and only two dynamo room, and it is worthy of notice here that this factory is entirely operated by water power, being,
probably, the only lamp factory so operated in the 150 volts and 250 lynamos are employed, two each of direct current; two of 500 volts and 50 amperes, used for treating purposes; and an alternating current inachine of 500 volts and 50 amperes capacity, which is of
special design and has been imported from Paris, and used for a special and improved method of treating the 50 volt lamps.
The water at present utilized is $225 \mathrm{~h}$. p., obtained
from from three Leffel water wheels, which are controlled
by a new electrical regulating device, designed by
Messrs. A. F. \& E. L. Oppermann, the electricians of the company. This apparatus maintains the power conchanges in load and enables the greatest uniformity to
be obtained in the product. Another noticeable feature is an Archimedean screw for forcing the mercury no the pumps, dispensing altogether with the vacuum The carbonizing room occupies all the remaining portion of the lower floor and is fitted up with specially
designed furnaces for the carbonizing of the filaments. designed furnaces for the carbonizing of the filaments.
On the next floor is the glass room, in which the glass On the next floor is the glass room, in which the glass
blowers are at work sealing in lamps and making pumps, etc. The pump room is also on this floor, an are of a specially modified Sprengel type, adapted for obtaining the highest possible vacuum, and having
several improvements over the ordinary Sprengel, being designed by Mr. W. H. Sauer, superintendent of The third floor is entirely devoted to the testing
oom, which is fitted up throughout with the necessary testing apparatus. For this department, Messrs.
Queen $\&$ Co., of Philadelphia, are now engaged in nanufacturing a new pattern photometer of the most delicate sensibility to meet the requirements of the
constantly increasing business. The treating department is provided for in the larger of the two other buildings and occupies both floors. courteously permitted to inspect this work, he had an opportunity to notice the extreme care and precision
with which every portion of the work, down to the with which every portion of the work, down to the
uost minute details, is carried out, and he can say homogeneity obtained by this process must necessarily be conducive to long life and high efficiency. Ten sets of treating apparatus are employed in this department the work is accomplished under this system. The
greatest care has been taken to prevent danger from greatest care has been taken to prevent danger from
fire, and should one break out it will be met with an The other two-ntory building, referred to above, is 